\title{
Vítimas de Violência: atendimento dos profissionais de enfermagem em Atenção Primária
}

\author{
Violence Victims: nursing professional attention in the Primary Care \\ Víctimas de Violencia: atendimiento de los profesionales de enfermería en Atención \\ Primaria
}

Recebido: $29 / 08 / 2018$
Aprovado: $15 / 03 / 2019$
Publicado: $01 / 07 / 2019$

\author{
Bruna Aparecida Rodrigues Duarte ${ }^{1}$ \\ Marcelle Aparecida de Barros Junqueira ${ }^{2}$ \\ Carla Denari Giuliani3
}

Esta é uma revisão integrativa que teve como objetivo buscar, analisar e cotejar a literatura referente à atenção às mulheres vítimas de violência doméstica no contexto da Atenção Primária à Saúde (APS) com enfoque na percepção dos profissionais de enfermagem. Para a busca, utilizou-se os descritores: violência contra a mulher, violência doméstica, atenção primária em saúde, nas bases de dados LILACS, MEDLINE, IBECS, BDENF, ColecionaSUS e BVS, entre os anos de 2012-2017, na íntegra, em português e inglês. Foram encontrados 73 artigos e selecionados 14 para este estudo. Verificou-se as seguintes categorias: Serviços da Atenção Primária de Saúde como porta de entrada para o atendimento de mulheres em situação, Falhas na identificação de situação de violência e na rede de apoio de violência e Percepção da equipe de enfermagem em relação à mulher vítima de violência doméstica. Observou-se que as atividades realizadas na APS possuem grande potencial para atendimento adequado à mulher vítima de violência. Porém, o bloqueio da equipe de reconhecer essas situações, em conjunto com diversos fatores, dificultam o processo. A APS apresenta-se como principal porta de entrada para a assistência de qualidade à mulher vítima de forma integralizada e holística, porém, demanda capacitação e fortalecimento da equipe.

Descritores: Violência contra a mulher; Violência doméstica; Atenção primária à saúde.

This is an integrative review aiming at searching, analyzing and comparing literature regarding the attention offered to women who are victims of domestic violence in the context of the Primary Healthcare (PH), focusing on the perception of nursing professionals. The following descriptors were used in the research: violence against women, domestic violence, primary healthcare. They were used in the databases LILACS, MEDLINE, IBECS, BDENF, Coleciona-SUS and VHL, from 2012 to 2017, for texts in English and Portuguese available in full. The research found 73 articles, from which 14 were selected in this study. The following categories were defined: Primary Healthcare as a gateway to the attention for women in situations of violence; Failure in the identification of violent situations and in the violence victim support network; and Perception of the nursing team regarding female victims of domestic violence. It was found that activities carried out in the $\mathrm{PH}$ have a high potential to offer adequate treatment to women who were the victims of violence. However, the team's own denial in the recognition of these situations, together with many other factors, make the process more difficult. The PH is the main gateway into a quality assistance for women victims of violence to find integral and hoslitic care. However, training and strengthening of the team are necessary.

Descriptors: Violence against women; Domestic violence; Primary health care.

Esta es una revisión integrativa que tuvo como objetivo buscar, analizar y cotejar la literatura referente a la atención a las mujeres víctimas de violencia doméstica en el contexto de la Atención Primaria a la Salud (APS) con enfoque en la percepción de los profesionales de enfermería. Para la búsqueda se utilizaron los descriptores: violência contra a mulher, violência doméstica, atenção primária em saúde, en las bases de datos LILACS, MEDLINE, IBECS, BDENF, Coleciona-SUS y, BVS; entre los años 2012-2017, en su versión completa, en portugués e inglés. Fueron encontrados 73 artículos y seleccionados 14 para este estudio. Se verificaron las siguientes categorías: Servicios de la Atención Primaria de Salud como puerta de entrada para el atendimiento de mujeres en situación, Fallas en la identificación de situación de violencia y en la red de apoyo de violencia y, Percepción del equipo de enfermería en relación a la mujer víctima de violencia doméstica. Se observó que las actividades realizadas en la APS poseen un gran potencial para atendimiento adecuado a la mujer víctima de violencia, sin embargo, el bloqueo del equipo de reconocer estas situaciones, en conjunto con diversos factores dificultan el proceso. La APS se presenta como principal puerta de entrada para asistencia de calidad a la mujer víctima de forma integral y holística, sin embargo, demanda capacitación y fortalecimiento del equipo.

Descriptores: Violencia contra la mujer; Violencia doméstica; Atención primaria de salud.

\footnotetext{
1. Acadêmica de Enfermagem da Universidade Federal de Uberlândia (UFU), MG, Brasil. ORCID: 0000-0003-0487-455X E-mail: brunaap150@hotmail.com

2. Enfermeira. Mestre e Doutora em Enfermagem Psiquiátrica. Pós Doutora em Enfermagem. Professora Associada do Programa de Pós Graduação em Saúde Ambiental e Saúde do Trabalhador da UFU, Uberlândia, MG, Brasil. ORCID: 0014-5010-2643-326098 E-mail: marcebarros@yahoo.com.br

3. Enfermeira. Mestre em Ciências Fisiológicas. Doutora em História e Cultura. Professora Adjunta na UFU, Uberlândia, MG, Brasil. ORCID: 0000-0001-5598-2230 E-mail: denarigiuliani@bol.com.br
} 


\section{INTRODUÇÃO}

A construção do que é a mulher na sociedade atual possui raízes históricas que solidificaram esse cenário. É interessante mencionar que a definição de mulher e o modo como ela deve ser tratada, foram mencionados pelo Código de Napoleão Bonaparte em 1804, que estabelecia a mulher como propriedade do esposo, e gerar filhos como sua primordial função, além de atribuir um conceito de honra intimamente ligado à sexualidade da mulher. Esse Código foi utilizado como fundamento para a criação do Código Civil Brasileiro de 1916, que vigorou até $2002^{1}$.

Essas desigualdades vêm pautadas em papéis sociais arraigados em culturas patriarcais reproduzidas na família, que construíram costumes que enxergam a mulher como um ser frágil, passivo, delicado e que deve estar ligado às tarefas domésticas, como cuidar dos filhos, do marido e da casa, enquanto o homem possui papéis de virilidade, coragem, agressividade e de chefe da família².

Nesse modelo de família, os atributos e os papéis de gênero valorizam o homem em detrimento da mulher, legitimando, por um lado, a dominação do homem, e por outro, a inferioridade da mulher. Nesse viés, edificase, no imaginário popular, o conceito da mulher destituída de autonomia do direito de decidir, inclusive sobre o seu próprio corpo. Essa imposição normativa constrói relações familiares permeadas pelo poder do masculino em relação ao feminino. Qualquer desvio dos padrões naturalizados pode desencadear conflitos e práticas violentas do homem em desfavor da mulher ${ }^{2}$.

Assim, diante das relações de poder entre homens e mulheres, entre público e privado, e dos processos violentos contra mulheres, faz-se necessário problematizar a questão de gênero, definida por Scott como "elemento constitutivo de relações sociais fundadas sobre as diferenças percebidas entre os sexos e o gênero, é um primeiro modo de dar significado às relações de poder"3. Em outro texto, Scott diz ainda que:

Por gênero me refiro ao discurso da diferença dos sexos. Ele não se relaciona simplesmente às ideias, mas também às instituições, às estruturas, às práticas cotidianas como aos rituais, e tudo o que constitui as relações sociais. $O$ discurso é o instrumento de entrada na ordem do mundo, mesmo não sendo anterior à organização social, é dela inseparável. Segue-se, então, que o gênero é a organização social da diferença sexual. Ele não reflete a realidade biológica primeira, mas ele constrói o sentido desta realidade. A diferença sexual não é a causa originária da qual a organização social poderia derivar; ela é antes, uma estrutura social móvel que deve ser analisada nos seus diferentes contextos históricos ${ }^{3}$.

Dessa forma, a violência contra as mulheres é resultado de um primeiro modo de dar significação às relações de poder entre sexos. A ideologia de dominação masculina não é só reproduzida por homens, mas também por mulheres que acreditam em sua inferioridade. E essa violência, que é um fenômeno histórico, complexo e de difícil definição, pode ser entendida como todo evento representado por relações, ações, negligências e omissões realizadas por indivíduos, grupos, classes e nações que ocasionam danos físicos, emocionais, morais e/ou espirituais a outrem. A origem da violência se encontra em todas as estruturas sociais, econômicas e políticas, bem como nas consciências individuais 4 .

Dentre as diversas formas de violência, a doméstica é caracterizada por agressividade e coação dentro do contexto familiar. Com a mudança de comportamento frente ao problema nos últimos anos e a forma como é reproduzida nas relações, a violência doméstica passou a ser interpretada como uma questão de saúde pautada nas relações de gênero. Existem diferentes tipos de violência contra a mulher, como: violência física, violência psicológica, violência sexual e violência patrimonial 5 .

A violência doméstica contra as mulheres, no Brasil e no mundo, configura um sério problema de saúde pública, por ser uma das principais causas de morbidade e mortalidade feminina ${ }^{6}$. A partir dos anos 1990, a sociedade, as autoridades e as instituições passaram a ter um olhar diferente frente à violência contra a mulher, com caráter preocupante em relação aos direitos humanos e à saúde. 
Frente a tantas mudanças em relação aos lugares que as mulheres ocuparam e conquistaram na sociedade, a violência começa a ser percebida e abordada de outra forma, mobilizando instituições, autoridades e os próprios envolvidos nesse contexto.

A partir dos anos 2000, surgem as políticas públicas de enfrentamento à violência contra a mulher, passando a ser ampliadas e incluídas em ações integradas, como: criação de normas e padrões de atendimento, aperfeiçoamento da legislação, incentivo à constituição de redes de serviços, apoio a projetos educativos e culturais de prevenção à violência e ampliação do acesso das mulheres à justiça e aos serviços de segurança pública ${ }^{7}$.

No Plano Nacional de Políticas para Mulheres, algumas propostas foram levantadas para o enfrentamento da violência contra as mulheres, dentre eles: implantar uma Política Nacional de Enfrentamento à Violência contra a Mulher; garantir o atendimento integral, humanizado e de qualidade às mulheres em situação de violência; reduzir os índices de violência contra as mulheres; garantir o cumprimento dos instrumentos e acordos internacionais e revisar a legislação brasileira de enfrentamento à violência contra as mulheres ${ }^{4}$.

Para essas metas, são sugeridos alguns passos, como: proceder a um diagnóstico quantitativo e qualitativo sobre os serviços de prevenção e atenção às mulheres em situação de violência em todo o território nacional, definir a aplicação de normas técnicas nacionais para o funcionamento dos serviços de prevenção e assistência às mulheres em situação de violência e integrar os serviços em redes locais, regionais e nacionais, além de instituir redes de atendimento às mulheres em situação de violência em todos os estados brasileiros ${ }^{4}$.

Especificamente no contexto da Atenção Primária à Saúde (APS), devido a seus princípios organizativos de territorialidade, integralidade, continuidade da assistência e articulação da rede de serviços de saúde, encontram-se as maiores possibilidades de prevenção, identificação e promoção de cuidados às mulheres que sofreram violência doméstica.

Os profissionais de saúde desses serviços devem estar atentos para garantir a autonomia da mulher frente aos seus direitos sexuais; observar problemas de saúde aparentemente comuns, mas associados à violência doméstica; realizar um acolhimento ético, responsável, com escuta ativa; e conhecer a rede intersetorial de serviços de apoio à mulher vitimizada 6 .

Este estudo tem como objetivo buscar, analisar e cotejar a literatura referente à atenção às mulheres vítimas de violência doméstica no contexto da Atenção Primária à Saúde (APS), com enfoque na percepção dos profissionais de enfermagem.

\section{MÉTODO}

Trata-se de uma Revisão Integrativa (RI). Esse método é definido pela análise sistemática sobre determinado assunto, viabilizando a síntese em apenas um trabalho e a contribuição crítica sobre os espaços que precisam ser preenchidos com novas pesquisas $^{8}$. A RI é uma metodologia que implica em uma estratégia científica que limita o viés de seleção por meio da síntese e da avaliação crítica dos artigos e sintetiza todos os estudos relevantes em um tópico específico ${ }^{9}$.

O processo de elaboração da revisão foi desenvolvido conforme as seis etapas descritas a seguir: 1) escolha do tema com estabelecimento da questão norteadora da pesquisa; 2) busca ou amostragem na literatura; 3) coleta de dados; 4) análise crítica dos estudos incluídos na revisão; 5) categorização dos estudos e discussão dos resultados; 6) apresentação da revisão integrativa. A questão escolhida como norteadora do trabalho foi: Como a violência contra a mulher é abordada na Atenção Primária à Saúde, principalmente pela equipe de enfermagem?

Assim, após a delimitação do problema, a busca por artigos foi realizada na Biblioteca Virtual em Saúde (BVS), e foram selecionados os artigos que responderam os critérios de inclusão: línguas inglesa e portuguesa; procurados com os descritores: "violência 
doméstica", "violência contra a mulher", "atenção primária à saúde".

Como filtros, foram selecionadas as seguintes bases de dados: Literatura Latinoamericana e do Caribe em Ciências da Saúde (LILACS), MEDLINE, IBECS, BDENF, Coleciona SUS. Assunto principal: violência contra a mulher, atenção primária à saúde, violência doméstica, saúde da mulher, maus tratos conjugais, violência, saúde da família, mulheres maltratadas, saúde pública, serviços de saúde, políticas públicas de saúde, violência sexual, atitude do pessoal de saúde, apoio social, equipe de assistência ao paciente, e direito da mulher. 0 período de publicação considerado foi de 2012 a 2017. 0 tipo de documento escolhido foi o artigo completo. 0 levantamento e a seleção das obras foram realizados em março de 2018.

Para a coleta de dados, inicialmente os artigos foram classificados por suas principais características técnicas, como: ano de publicação, país de origem, idioma, periódico, título e desenho do estudo.

Em seguida, os artigos foram avaliados e categorizados por meio da análise temática, que consistiu em três etapas: exploração do material; tratamento dos resultados obtidos e interpretação. Inicialmente foi realizada uma pré-análise com identificação das palavras chave; em um segundo momento, foram realizados recortes das partes mais importantes dos artigos; depois, os dados foram agrupados e interpretados por temas.

\section{RESULTADOS}

Após a busca com os descritores "violência doméstica", "violência contra a mulher", "atenção primária à saúde", foram encontrados 73 artigos, depois de aplicados os filtros, 35 artigos, e, após a leitura dos títulos e resumos, foram excluídos 24 artigos que não correspondiam à questão norteadora. Considerou-se, portanto, 14 artigos que corresponderam ao questionamento proposto. A figura 1 demonstra os passos para a seleção dos artigos que compuseram esta RI, desde o cruzamento dos descritores, passando pelos passos propostos pela metodologia, até a inclusão final dos artigos.

Figura 1. Etapas para seleção dos artigos incluídos. Uberlândia, 2018.

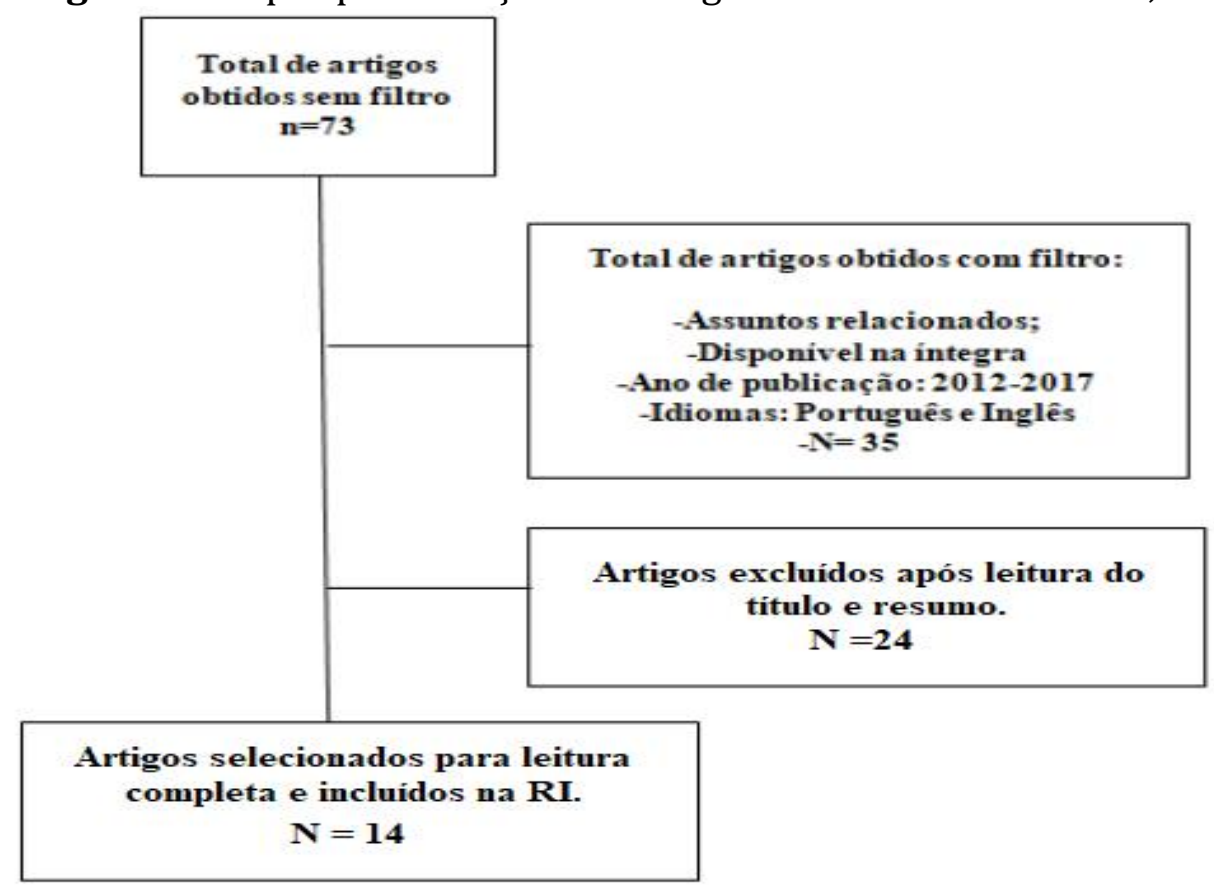

Fonte: Autoras

Assim, realizou-se a leitura, as análises dos textos e o preenchimento do instrumento de coleta de dados. Essas publicações foram agrupadas na Tabela 1. Pode-se observar que a maioria dos estudos foi publicada no ano de 2013 
(37,7\%), no Brasil $(92,8 \%)$, em português $(92,8 \%)$ e com delineamento qualitativo $(64,2 \%)$.

Nos objetivos dos estudos, percebe-se que há o predomínio de análises dos serviços de APS em relação às mulheres vítimas de violência doméstica, às formas de enfrentamento da violência nas UBS e ao comportamento dos profissionais no processo de acolhimento de vítimas de violência por parceiro íntimo. Em alguns estudos, buscou-se entender quais são os fatores potencializadores e dificultadores para a relação entre o profissional e a mulher em situação de violência usuária da unidade de saúde.

Tabela 1. Artigo segundo o ano de publicação, país de origem, idioma, instituição sede, periódico, título, delineamento. Uberlândia, 2018.

\begin{tabular}{|c|c|c|c|c|c|}
\hline Estudo & Ano/Origem & Idioma & Periódico & Título & Desenho \\
\hline 1 & 2012/Brasil & Português & $\begin{array}{l}\text { Revista de Saúde } \\
\text { Pública }\end{array}$ & $\begin{array}{l}\text { Violência entre usuárias de Unidades de } \\
\text { Saúde: prevalência, perspectiva e } \\
\text { conduta de gestores de enfermagem }\end{array}$ & $\begin{array}{l}\text { Pesquisa } \\
\text { Quantitativa, } \\
\text { Descritiva. }\end{array}$ \\
\hline 2 & 2012/Brasil & Português & $\begin{array}{lr}\text { Revista } & \text { Brasileira } \\
\text { Saúde } & \text { Materno } \\
\text { Infantil } & \end{array}$ & $\begin{array}{l}\text { Violência contra mulher na rede de } \\
\text { Atenção Básica: o que os enfermeiros } \\
\text { sabem sobre esse problema? }\end{array}$ & $\begin{array}{l}\text { Pesquisa } \\
\text { Quantitativa, } \\
\text { Transversal, } \\
\text { Descritiva. }\end{array}$ \\
\hline 3 & 2013/Brasil & Português & $\begin{array}{l}\text { Acta Paul } \\
\text { Enfermagem }\end{array}$ & $\begin{array}{l}\text { Violência contra a mulher: limites e } \\
\text { potencialidades na prática assistencial }\end{array}$ & $\begin{array}{l}\text { Pesquisa } \\
\text { Qualitativa, } \\
\text { análise } \\
\text { grupal. }\end{array}$ \\
\hline 4 & 2013/Brasil & Português & $\begin{array}{ll}\text { Cadernos } & \text { de } \\
\text { Saúde Pública } & \end{array}$ & $\begin{array}{l}\text { Violência Doméstica contra mulheres e } \\
\text { a atuação profissional na Atenção } \\
\text { Primária à Saúde: Um estudo } \\
\text { etnográfico em Matinhos, Paraná, Brasil }\end{array}$ & $\begin{array}{l}\text { Pesquisa } \\
\text { Qualitativa, } \\
\text { Estudo } \\
\text { Etnográfico. }\end{array}$ \\
\hline 5 & 2013/Brasil & Português & Escola Ana Nery & $\begin{array}{l}\text { Significado da capacitação profissional } \\
\text { para o cuidado de mulher vítima de } \\
\text { violência conjugal }\end{array}$ & $\begin{array}{l}\text { Pesquisa } \\
\text { Qualitativa. }\end{array}$ \\
\hline 6 & 2013/Brasil & Português & $\begin{array}{lr}\text { Revista } & \text { de } \\
\text { Enfermagem } & \text { do } \\
\text { Centro } \quad \text { Oeste } \\
\text { Mineiro }\end{array}$ & $\begin{array}{l}0 \text { cuidado de enfermagem à mulher } \\
\text { vítima de violência doméstica }\end{array}$ & $\begin{array}{l}\text { Revisão } \\
\text { Integrativa. }\end{array}$ \\
\hline 7 & 2013/Brasil & Português & $\begin{array}{l}\text { Psicologia } \\
\text { Argumento }\end{array}$ & $\begin{array}{l}\text { Abordagem da violência familiar na } \\
\text { Estratégia Saúde da Família: uma } \\
\text { revisão de literatura }\end{array}$ & $\begin{array}{l}\text { Revisão de } \\
\text { Literatura. }\end{array}$ \\
\hline 8 & 2014/Brasil & Português & $\begin{array}{l}\text { Saúde e Sociedade } \\
\text { de São Paulo }\end{array}$ & $\begin{array}{l}\text { A construção do cuidado: o } \\
\text { atendimento às situações de violência } \\
\text { doméstica por equipes de saúde da } \\
\text { família }\end{array}$ & $\begin{array}{l}\text { Pesquisa } \\
\text { Qualitativa. }\end{array}$ \\
\hline 9 & 2014/Brasil & Português & $\begin{array}{l}\text { Comunicação } \\
\text { Saúde Educação }\end{array}$ & $\begin{array}{l}\text { O objeto, a finalidade e os instrumentos } \\
\text { do processo de trabalho em saúde na } \\
\text { atenção à violência de gênero em um } \\
\text { serviço de Atenção Básica }\end{array}$ & $\begin{array}{l}\text { Pesquisa } \\
\text { Qualitativa. }\end{array}$ \\
\hline 10 & 2015/Brasil & Inglês & Paideia & $\begin{array}{l}\text { The significant social networks of } \\
\text { women who have resided in shelters }\end{array}$ & $\begin{array}{l}\text { Pesquisa } \\
\text { Qualitativa. }\end{array}$ \\
\hline 11 & 2015/Brasil & Espanhol & Gaceta Sanitaria & $\begin{array}{l}\text { Uso de la evaluación realista para } \\
\text { evaluar las respuestas de los equipos de } \\
\text { Atención Primaria a la violencia del } \\
\text { compañero íntimo en España }\end{array}$ & $\begin{array}{l}\text { Pesquisa } \\
\text { Quantitativa } \\
\text {-Qualitativa. }\end{array}$ \\
\hline 12 & 2015/Brasil & Português & $\begin{array}{l}\text { Journal of Human } \\
\text { Growth and } \\
\text { Development }\end{array}$ & $\begin{array}{l}\text { Análise da violência doméstica na saúde } \\
\text { das mulheres }\end{array}$ & $\begin{array}{l}\text { Pesquisa } \\
\text { Qualitativa } \\
\text { Exploratório }\end{array}$ \\
\hline 13 & 2017/Brasil & Português & Enferm. Foco & $\begin{array}{l}\text { Atuação dos enfermeiros da atenção } \\
\text { básica a mulheres em situação de } \\
\text { violência }\end{array}$ & $\begin{array}{l}\text { Pesquisa } \\
\text { Qualitativa. }\end{array}$ \\
\hline 14 & 2017/Brasil & Português & Rev Enferm UERJ & $\begin{array}{l}\text { Representação social de profissionais } \\
\text { de enfermagem acerca da violência } \\
\text { doméstica contra a mulher: abordagem } \\
\text { estrutural }\end{array}$ & $\begin{array}{l}\text { Pesquisa } \\
\text { Qualitativa, } \\
\text { Descritivo. }\end{array}$ \\
\hline
\end{tabular}




\section{DISCUSSÃO}

A violência contra a mulher é considerada como um problema de saúde pública desde 1996. Assim, é necessário que o profissional de saúde esteja capacitado para atuar nesses cenários, buscando a resolução do problema ou a diminuição dele.

Nessa revisão, os estudos foram divididos em categorias, para melhor apresentação dos resultados. Assim, diferentes artigos foram agrupados em uma mesma categoria, de acordo com o que foi evidenciado na mesma. Três categorias foram construídas: Serviços da Atenção Primária de Saúde como porta de entrada para o atendimento de mulheres em situação de violência; Falhas na identificação de situação de violência e na rede de apoio de violência; $\mathrm{e}$, Percepção da equipe de enfermagem em relação à mulher vítima de violência doméstica.

Serviços da Atenção Primária de Saúde como porta de entrada para o atendimento de mulheres em situação de violência

Os serviços oferecidos na APS como a Estratégia de Saúde da Família (ESF) consistem em uma porta de entrada para o acolhimento e atendimento das mulheres em situação de violência por diversos fatores, iniciando-se pela possibilidade de detecção precoce dos casos, o que se deve à aproximação entre a equipe e a realidade das usuárias daquele território 10,11.

Quatro artigos ${ }^{3,4,10,13}$ abordaram a importância do acolhimento de qualidade, por ser uma das ações dentro das UBS's que, quando trabalhadas com humanização e integralização do cuidado, se caracterizam como grandes potencializadoras para a criação de vínculos e, logo, de confiança entre as usuárias e a equipe, o que pode facilitar a detecção de situações de violência. Nesse momento, é necessário que ocorra a escuta ativa da mulher, buscando compreender suas queixas, angústias e sofrimentos, possibilitando o melhor planejamento de acordo com a rede disponível, com o intuito de melhor apoiá-la, atentando-se ao cuidado além do tratamento de lesões físicas e a prescrição de medicamentos, caso seja necessário, mas atentando também a indícios de depressão, ansiedade, crises nervosas e outros $^{12}$.

Como porta de entrada, na UBS é possível o diálogo e, conforme a situação, repassar as informações legais e de direito da mulher, sempre respeitando a vontade dela de seguir ou não esse caminho. Quando ocorre a denúncia, a mulher passará por diferentes instituições, e esse processo pode ser sofrido, pois ela estará revivendo os momentos de agressão a cada novo profissional que procurar. Por isso, a importância da intersetorialidade, a necessidade de que as instituições se comuniquem, e de que os profissionais repassem o caso, evitando a revitimização da mulher violentada ${ }^{13-15}$.

Outro fator importante da APS é a elaboração de planos de ações que devem agir em conjunto com a equipe multiprofissional e de forma singular, atentando-se para a realidade de cada mulher em específico, incluindo-a em todo o processo de estabelecimento de metas, como também o agressor, buscando perceber o problema e oferecer possibilidades de resolução. Por exemplo, nos casos de abuso do álcool e outras drogas, considerados como fatores disparadores de violência ${ }^{16}$, encaminhando para as instituições de tratamento disponíveis na rede, conforme sua vontade.

Outro momento importante disponível pela APS e discutida nos estudos $3,4,6,8$ é a visita domiciliar, uma ação que possibilita a visão da realidade daquela mulher, como também a construção de vínculo entre os profissionais e a comunidade, contribuindo para que a mulher consiga falar sobre os acontecimentos e, a partir de então, tenha assistência. 0 agente comunitário de saúde (ACS) é o profissional que melhor estabelece essa ligação com a vítima, devido às visitas periódicas que geram contato próximo e de confiança, tornando-o apto a detectar e acolher questões como a violência contra a mulher11,14,15,17.

\section{Falhas na identificação de situação de violência e na rede de apoio}

0 estudo 4 discute que um dos problemas dos profissionais em não identificar o cenário de violência deve-se ao modelo biomédico, o qual ainda predomina nas unidades de saúde, onde os profissionais se atentam à doença, com 
uma visão focada no problema físico e clínico, enquanto, para identificar casos de violência, é importante não se limitar às condutas hospitalocêntricas, focadas apenas em problemas clínicos, é preciso utilizar ferramentas que sensibilizem a escuta, para um cuidado integral da mulher vítima, com o apoio de uma equipe multiprofissional ${ }^{14}$.

Colaborando com essa ideia, o estudo 9 aponta essa assistência tradicional e fragmentada como produtora de exclusão de ações de caráter preventivo e de promoção da saúde, assim como aponta o fato de que os profissionais encaminham a mulher aos psicólogos por entenderem ser o único profissional capaz de resolver as situações de violência, tratando a violência doméstica, assim, como um problema de saúde mental ${ }^{18}$.

A falta de capacitação dos profissionais é um dos principais motivos da dificuldade em conduzir os casos, acontecendo muitas vezes de serem omitidos pelo medo de denunciar, e pela impotência de não saber direcionar a vítima. Por isso, muitos acabam não notificando os casos e, quando abordados, as condutas são inadequadas, tornando o atendimento ineficaz ${ }^{19}$.

0 estudo 5 demonstra que, na fala dos profissionais, há queixas de não saberem qual é a melhor conduta, e que na maioria das vezes não questionam o problema por medo de não saber como irão lidar com a situação, caso ela seja revelada pela vítima ${ }^{19}$. Por não saberem reconhecer o agravo e os encaminhamentos à mulher, esse constitui-se o principal desafio para o enfrentamento da problemática ${ }^{19}$.

Os estudos ainda apontam que o problema do manejo com a violência doméstica vem desde o período de graduação, no qual existe um grande deficit na formação de alunos de graduação em enfermagem e na área de saúde em geral. $\mathrm{Na}$ abordagem e atendimento às vítimas de violência doméstica, os currículos são pouco articulados com as mudanças nos parâmetros e contextos sociais, e tampouco convergem com as políticas de saúde publicadas há pouco tempo ${ }^{19,20,21 .}$.

Nesse sentido, os profissionais vão para os serviços inexperientes e precisam participar de cursos de Educação Permanente em Saúde, o que pode proporcionar momentos de discussão entre os profissionais e melhorias no serviço prestado ${ }^{19,20,21}$.

Assim, pode-se perceber, até o momento, que o não reconhecimento da violência nos serviços de saúde é provocado por diversos fatores, entre eles a dificuldade relatada pelos profissionais de intervir em assuntos tidos como delicados e íntimos. Mesmo que haja divulgação nos meios de comunicação, permitindo que este se torne um problema público, que se busque romper com o caráter exclusivamente privado do fenômeno e criar mecanismos para sua prevenção e solução a partir da responsabilização social do problema, a intervenção pública ainda acontece de forma discreta e com pouco efeito, visto que essa problemática ainda é vista como assunto exclusivo do casal ${ }^{18}$.

Os números registrados de violência contra a mulher apontam que a violência não é problema exclusivo do casal, ele tem dimensão pública e deve ser realizada a intervenção por parte de órgãos públicos de saúde, com vistas a oferecer atendimentos e medidas de prevenção e queda no número de novos casos e reincidência.

Em contrapartida, há artigos que fogem do modelo hospitalocêntrico, focando em um importante desafio, o de não reproduzir no interior da UBS o modelo de "encaminhamento" que não visa a resolução do problema, mas a responsabilização de outros profissionais e não de si mesmo ${ }^{23}$.

Observou-se a preocupação dos profissionais do Núcleo de Apoio à Saúde da Família (NASF) em valorizar a discussão dos casos e seus desdobramentos com toda a equipe de saúde da família, mas essas intervenções conjuntas foram realizadas principalmente pela assistente social e as ACS, sendo escassos os momentos em que se propôs uma atuação conjunta com médicos, enfermeiros e técnicos de enfermagem. Em outras palavras, na própria organização das ações dos serviços, acaba-se reforçando a cisão entre aspectos sociais e biomédicos, dificultando a incorporação desses saberes na prática de todos os profissionais ${ }^{11,19}$. 
A influência das relações de gênero são apresentadas nos artigos 8 e 9 como as principais causas de violência entre homem e mulher, citando pesquisas que apontam que os profissionais se confundem na definição de gênero e, de certa forma, reforçam a posição de poder que o homem exerce sobre a mulher, muitas vezes justificando a violência por comportamentos padronizados e culturais que a figura feminina deveria seguir dentro da sociedade ${ }^{11,19}$.

Percepção da equipe de enfermagem em relação à mulher vítima de violência doméstica Os estudos apresentam a APS como principal porta de entrada para o atendimento das mulheres vítimas, e também a equipe de enfermagem como meio estratégico para acolher essas mulheres, devido à aproximação e também pelo fato de a enfermeira ter como responsabilidade capacitar os ACS para visitar e perceber possíveis situações de violência, pois eles são a ponte para a equipe.

0 estudo 13 apresentou os possíveis agravos que a vítima de violência pode desenvolver, mostrando, assim, o conhecimento da equipe em relação a problemas tão sérios. Mas, em contrapartida, afirma nas unidades a ficha de notificação compulsória que é instrumento extremamente necessário para a criação de políticas e estratégias de resolução e diminuição dos ciclos de violência ${ }^{23}$. Outrossim, há o hábito de se encaminhar a mulher para outros profissionais/instituições por falta de conhecimento para abordar a vítima e sobre os próximos passos a serem dados com o intuito de buscar uma solução para o problema ${ }^{23}$.

Seguindo nesse ponto, o estudo 14 apresenta a representação que a equipe responsável por esse cuidado carrega, o que influencia no atendimento à vítima, pois, nessas situações de vulnerabilidade, são extremamente necessários o acolhimento e a detecção dos casos de violência e, para isso, os profissionais precisam estar livres de preconceitos e julgamentos ${ }^{10}$.

Uma das percepções obtidas por meio desta pesquisa ${ }^{10}$ foi em relação à revolta dos profissionais quando a vítima de violência retorna para o agressor. Isso dificulta a relação profissional - usuária, podendo ocasionar ruptura do vínculo, o que deve ser remediado com cuidado, pois as decisões devem estar em total posse das usuárias, e a equipe deve buscar, junto com ela, possibilidades de ruptura do ciclo de violência.

Já nos estudos 3, 4 e 6 os pesquisadores apontam que os participantes são contra a formação de protocolos, pois acreditam que rotinas pré-estabelecidas não cabem para casos de violência doméstica, e apontam que atendimentos padronizados não oferecem acolhimento de qualidade, sendo necessário ter fluxos traçados ${ }^{14,15,17}$.

No entanto, é fundamental levar em consideração a especificidade de cada caso, da vítima, do contexto da situação e das relações estabelecidas. 0 artigo aponta a necessidade de tecnologias leves, capazes de considerar a inter-relação e as intersubjetividades de cada caso $^{15}$.

Considerar a singularidade da vítima leva a equipe a formular o Projeto Terapêutico Singular (PTS), que envolve o autocuidado e a atuação multiprofissional no caso, proporcionando um vínculo empático entre profissionais e usuária ${ }^{15,16}$.

Em contrapartida, os estudos 6 e 15 apontam a ausência de protocolos específicos e a falta de parâmetros técnicos e científicos essenciais no âmbito $\mathrm{da}$ racionalidade biomédica ${ }^{14,24}$. Essa ausência pode contribuir para que esses profissionais não se considerem responsabilizados por atuar com essas mulheres como parte do exercício de suas funções ${ }^{24}$. No estudo 5 , os entrevistados falaram sobre a importância de recorrer ao protocolo de manejo de casos suspeitos de violência contra a mulher do Ministério da Saúde, porém, esse protocolo só existe para atendimento a vítimas de violência sexual ${ }^{19}$.

\section{CONCLUSÃO}

A violência contra a mulher é cada vez mais preocupante para a sociedade, para os órgãos públicos e profissionais, pois os números de violência crescem consideravelmente e os profissionais, principalmente os da saúde, não estão preparados para o manejo dos casos que 
surgem nas unidades, muitas vezes com sinais de violência doméstica.

Os casos de violência doméstica não são identificados devido ao despreparo dos profissionais sobre como abordar a vítima, à dificuldade dos profissionais para correlacionar outros serviços protetivos, entendendo que violência doméstica seria algo correlacionado com o ambiente domiciliar, onde esse profissional não deve ter acesso.

Assim, a vítima dessa violência fica vulnerável a outros acontecimentos violentos, dificultando o seu adequado enfrentamento. Essas mulheres, de tal modo permeadas pelo medo das consequências de relatar os casos de agressão, continuam no processo violência.

Os profissionais das unidades de atenção primária em saúde precisam ser capacitados em atividades de educação permanente para fortalecer algumas das ações que já são desenvolvidas, como o acolhimento que trabalha pela política de humanização e proporciona uma escuta qualificada ao usuário, o trabalho em equipe multiprofissional, a formulação de projetos terapêuticos que envolvam profissionais de diferentes áreas e a vítima, a busca pelo apoio da equipe do NASF caso haja no município, e fortalecer as visitas domiciliares, tidas pelos estudos como uma ação de forte potencial, pois proporciona aos profissionais e, em especial, aos agentes comunitários de saúde, maiores possibilidades de observar sinais de possível vítima, por conhecerem o contexto em que a família vive e fortalecer o vínculo com os usuários.

Os estudos não citaram quais são os protocolos preconizados pelas unidades de saúde, nem se os municípios implantaram condutas a serem seguidas dentro das unidades. Porém, a maioria defende que a criação de protocolos poderia limitar a assistência, e os profissionais agiriam de forma mecanizada, não respeitando a particularidade de cada caso.

É importante padronizar a notificação compulsória dentro das unidades para que haja estudos epidemiológicos referentes aos casos de violência e, assim, a criação de novas políticas públicas de enfrentamento à violência, medidas de prevenção, evitando novos casos e reincidência, além de envolver profissionais de diferentes áreas, aumentando a responsabilização pública sobre os casos.

De forma geral, entende-se a necessidade de uma rede firme entre as instituições de saúde e segurança pública para o enfrentamento da violência contra a mulher, como também a prevenção desses casos. Assim, não basta criar políticas e programas, é importante que ocorram também constantes avaliações dos processos e do impacto das ações, para corrigir e aprimorar o seu desempenho.

Compreender as possibilidades de formação dessas redes, e de como podem atuar parece um bom caminho para futuras pesquisas. 0 baixo número de artigos encontrados sobre o tema e que seguiam os critérios pode ser considerado como uma limitação do presente estudo.

\section{REFERÊNCIAS}

1. Negrão T. Saúde e violência de gênero. In: Sandenberg CMB, Tavares MS, organizadoras. Violência de gênero contra mulheres. Salvador: EDUFBA; 2016. p. 109-144.

2. Oliveira EM, Jorge MSB. Violência contra mulher: sofrimento psíquico e adoecimento mental. Rev RENE. [Internet]. 2007 [citado em 18 mar 2018]; 8(2):93-100. Disponível em: http://www.periodicos.ufc.br/rene/article/v iew/5332.

DOI: http://dx.doi.org/10.15253/rev\%20rene.v8i 2.5332

3. Scott J. Gênero: uma categoria útil de análise histórica. Educ \& Realid. [Internet]. 1995 [citado em 18 mar 2018]; 20(2):71-99. Disponível em: https://seer.ufrgs.br/educacaoerealidade/ar ticle/view/71721

4. Ministério da Saúde (Br), Secretaria de Vigilância em Saúde, Departamento de Análise de Situação de Saúde. Impacto da Violência na Saúde dos Brasileiros. Brasília, DF: Ministério da Saúde; 2005.

5. Costa LHR. Estendendo o Fio de Ariadne: sexualidade feminina e a interseção com o cuidado nos discursos de enfermeiras [Tese]. Salvador: Universidade Federal da Bahia/UFBA; 2011. 
6. Ministério da Saúde (Br); Instituto SírioLibanês de Ensino e Pesquisa. Protocolos de Atenção Básica: saúde das mulheres [Internet]. Brasília, DF: Ministério da Saúde; 2016 [citado em 20 mar 2018]. Disponível em: http://bvsms.saude.gov.br/bvs/publicacoes/ protocolos_atencao_basica_saude_mulheres.p df

7. Celmer EG. Violência conjugal contra a mulher: refletindo sobre gênero, consenso e conflito na justiça criminal. Ártemis. [Internet]. 2007 [citado em 18 mar 2018]; 6:26-37. Disponível em: http://periodicos.ufpb.br/ojs/index.php/art emis/article/view/2122

8. Souza MT, Silva MD, Carvalho R. Integrative review: what is it? How to do it? Einsten. [Internet]. 2010 [citado em 19 mar 2018]; 8(1):102-6. Disponível em: http://www.scielo.br/scielo.php?script=sci_a rttext\&pid=S1679-45082010000100102 DOI: $\quad$ http://dx.doi.org/10.1590/s167945082010rw1134

9. Mendes KDS, Silveira RCCP, Galvão CM. Revisão Integrativa: método de pesquisa para a incorporação de evidências na saúde e na enfermagem. Texto \& Contexto Enferm. [Internet]. 2008 [citado em 19 mar 2018]; 17(4): 758-64. Disponível em: http://www.scielo.br/scielo.php?script=sci_a rttext\&pid=S0104-07072008000400018

DOI: $\quad$ http://dx.doi.org/10.1590/S010407072008000400018

10. Amarijo CL, Gomes VLO, Gomes AMT, Fonseca AD, Silva CD. Representação social de profissionais de enfermagem acerca da violência doméstica contra a mulher: abordagem estrutural. Rev Enferm UERJ. [Internet]. 2017 [citado em 20 mar de 2018]; 25(2). Disponível em: https://www.epublicacoes.uerj.br/index.php/enfermagemu erj/article/view/23648/22019 DOI: http://dx.doi.org/10.12957/reuerj.2017.236 48

11. Moreira TNF, Martins CL, Feuerwerker LCM, Schraiber LB. A construção do cuidado: o atendimento às situações de violência doméstica por equipes de saúde da família. Saúde Soc. [Internet]. 2014 [citado em 20 mar 2018]; 23(3): 814-27. Disponível em: http://www.scielo.br/pdf/sausoc/v23n3/01 04-1290-sausoc-23-3-0814.pdf

DOI:

https://doi.org/10.1590/S0104-

12902014000300007

12. Silva SA, Lucena KDT, Deininger LSC, Coelho HFC, Vianna RPT, Anjos UU. Análise da violência doméstica na saúde das mulheres. Rev Bras Crescimento Desenvolv Hum. [Internet]. 2015 [citado em 20 de mar 2018]; 25(2): 182-6. Disponível em: http://pepsic.bvsalud.org/pdf/rbcdh/v25n2 /pt_08.pdf http://dx.doi.org/10.7322/JHGD.103009

13. Krenkel SK, Moré Cloo, Motta CCL. The significant social networks of women who have resided in shelters. Paidéia. [Internet]. 2015 [citado em 20 mar 2018]; 25(60):125$33 . \quad$ Disponível em: http://www.scielo.br/scielo.php?script=sci_a rttext\&pid=S0103-863X2015000100125

14. Signorelli MC, Auad D, Pereira PPG. Violência doméstica contra mulheres e a atuação profissional na atenção primária à saúde: um estudo etnográfico em Matinhos. Cad Saúde Pública. [Internet]. 2013 [citado em 19 de mar de 2018]; 29(6): 1230-40. Disponível

em: http://www.scielo.br/pdf/csp/v29n6/a19v2 9n6.pdf

15. Silva EB, Padoin SMM, Vianna LAC. Violência contra a mulher: limites e potencialidades da prática assistencial. Acta Paulista Enferm. [Internet]. 2013 [citado em 20 mar 2018]; 26(6):608-13. Disponível em: http://www.scielo.br/pdf/ape/v26n6/16.pd f DOI: http://dx.doi.org/10.1590/S010321002013000600016.

16. Presidência da República (Brasil), Secretaria Especial de Atendimentos para as Mulheres. Plano Nacional de Políticas para as Mulheres. Brasília, DF: Presidência da República; 2005.

17. Aguiar RS. O cuidado de enfermagem à mulher vítima de violência doméstica. Rev Enferm Cent Oeste Min. [Internet]. 2013 [citado em 20 mar 2018]; 3(2):723-31. Disponível em: http://www.seer.ufsj.edu.br/index.php/reco $\mathrm{m} /$ article/view/358 DOI: http://dx.doi.org/10.19175/recom.v0i0.358 18. Almeida LR, Silva ATM, Machado LS. O objeto, a finalidade e os instrumentos do 
processo de trabalho em saúde na atenção à violência de gênero em um serviço de atenção básica. Interface (Botucatu, Online). [Internet]. 2014 [citado em 20 mar 2018]; 18(48):47-60. Disponível em: http://www.scielo.br/pdf/icse/v18n48/180 7-5762-icse-18-48-0047.pdf http://dx.doi.org/10.1590/180757622014.0560

19. Gomes NP, Erdmann AL, Bettinelli LA, Higashi GDC, Carneiro JB, Diniz NMF. Significado da capacitação profissional para o cuidado da mulher vítima de violência conjugal. Esc Anna Nery Rev Enferm. [Internet]. 2013 [citado em 21 mar 2018]; 17(4):683-9. Disponível em: http://www.scielo.br/pdf/ean/v17n4/14148145-ean-17-04-0683.pdf http://dx.doi.org/10.5935/14148145.20130012

20. Mendonça ET, Souza LV. A violência doméstica contra a mulher como questão de saúde pública. Rev Enferm UFPE on line. [Internet]. 2010 [citado em 21 mar 2018]; 4(2):872-81. Disponível em: http://bases.bireme.br/cgibin/wxislind.exe/i ah/online/?IsisScript=iah/iah.xis\&src=googl e\&base $=$ BDENF\&lang $=p \&$ nextAction $=\operatorname{lnk} \&$ ex prSearch $=20180$ \&indexSearch $=$ ID

21. Baraldi ACP, Almeida AM, Perdoná GC. Violência contra a mulher na rede de atenção básica: o que os enfermeiros sabem sobre o problema? Rev Bras Saúde Mater Infant. [Internet]. 2012 [citado em 21 mar 2018]; 12(3):307-18. Disponível em: http://www.scielo.br/pdf/rbsmi/v12n3/a10 v12n3.pdf

DOI:

http://dx.doi.org/10.1590/S1519-

38292012000300010

22. Schmidt B, Coelho ESB. Abordagem da violência familiar na Estratégia Saúde da Família: revisão de literatura. Psicol Argum. [Internet]. 2013 [citado em 21 de mar 2018]; 31(74):373-81. Disponível em: https://periodicos.pucpr.br/index.php/psico logiaargumento/article/view/19633 DOI: 10.7213/psicol.argum.31.074.DS01

23. Silva NNFS, Leal SMC, Trentin D, Vargas MAO, Vargas CP, Vieira LB. Atuação dos enfermeiros da atenção básica a mulheres em situação de violência. Enferm Foco. [Internet]. 2017 [citado em 23 mar 2018]; 8(3):70-7. Disponível em: http://revista.cofen.gov.br/index.php/enfer magem/article/view/1290

24. Osis MJD, Duarte GA, Faundes A. Violência entre usuárias de unidades de saúde: prevalência, perspectiva e conduta de gestores e profissionais. Rev Saúd Púb. [Internet]. 2012 [citado em 21 mar 2018]; 46(2):351-8. Disponível em: http://www.scielo.br/pdf/rsp/2012nahead/ 3137.pdf

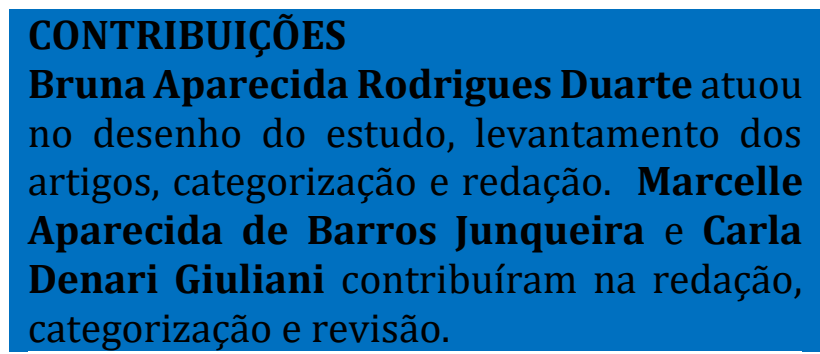

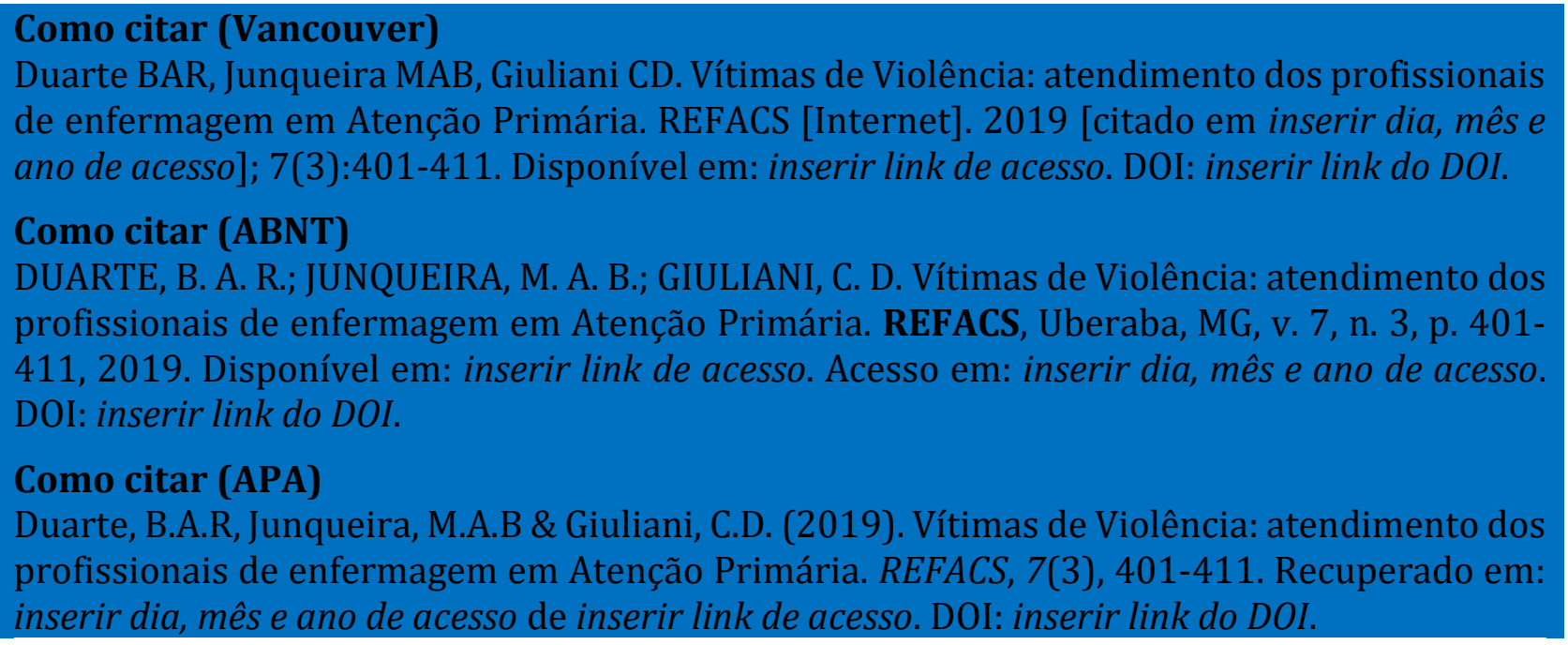

